\title{
STUDY ON THE FACTORS FOR MENSTRUAL DYSFUNCTION IN FEMALE ATHLETES
}

\author{
Galina Vanlyan, Diana Dimitrova
}

\begin{abstract}
:
The aim of the present study was to determine the prevalence of menstrual dysfunction among sportswomen and to examine the importance of disordered eating behaviors and other selected factors for its occurrence. 281 women

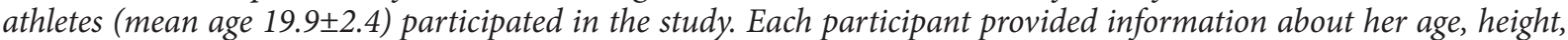
weight, use of contraceptive drugs, sports experience, and completed a screening questionnaire meant to identify the age of menarche, primary amenorrhea, secondary amenorrhea, oligomenorrhea and contraceptive use. The women athletes were divided into 2 groups according to their menstruation status - eumenorrheic (EM) and with menstrual dysfunction (MD) (amenorrhea/oligomenorrhea). All participants completed an anonymous EDE-Q. A mean cut-off of $\geq 4.0$ for the subscales - WC, SC, DR or GS was used to classify the athletes as having disordered eating, as well as if they have been practiced pathogenic behavior on $\geq 2$ days in the preceding 28 days. Comparison analyses between both groups of athletes were carried out by t-test, Mann-Whitney test and Chi-square test using SPSS-23. Menstrual dysfunction was found in $8.9 \%$ of the athletes, $16.6 \%$ of them were with high value of one of the subscales of EDE-Q and 36.3\% of the respondents reported practicing pathogenic behavior. The results showed relatively low incidence of athletes with both eating disorder and menstrual dysfunction (4.98\%). We have failed to detect any significant difference between the EM and MD group with respect to their mean weight, BMI, sports experience, contraceptive use and the values of the EDE-Q scales. The average age of menarche of the MD group (14.5 \pm 1.5$)$ was significantly delayed as compared to EM group (13.3 \pm 1.5$)$. The proportion of athletes with elevated values of Weight Concern was higher in MD group (20\%) vs. $\mathbf{7 . 8 \%}$ in EM group $(\alpha<0.05)$.
\end{abstract}

Key words: athletes, eating disorders, amenorrhea, oligomenorrhea, EDE-Q

\section{Introduction:}

Over the last three decades, the number of women engaged in sport competitions has been growing rapidly. There is undoubtedly the beneficial impact of sport on physical and mental health. However, a significant increase in the volume of physical exercises may adversely affect somatic growth, biological maturation and reproductive functions of female athletes (Roupas, Georgopoulos, 2011).

Studies conducted by a number of authors have indicated that there is an increased risk of Female athlete triad, a syndrome which includes three inter-related conditions - eating disorders, menstrual dysfunctions and decreased bone density (Nichols et al., 2006; 2007; Raymond-Barker et al., 2007; Forsberg, Lock, 2006).

According to modern conceptions, low energy availability or energy deficiency disrupts the reproductive system and that result in menstrual abnormalities (Nattiv et al., 2007; Loucks, 1990).

The reproductive function's abnormalities occur in $6-79 \%$ of women who practice sports (Warren, Perlroth, 2001). The most common menstrual disorders in female athletes include oligomenorrhea; primary and secondary amenorrhea (Carr, 1992).
The prevalence of secondary amenorrhea and oligomenorrhea varies widely $(1-79 \%)$ in female athletes, while in the general population it is significantly lower 2-5\% (American Academy of Pediatrics, 1989; Nattiv et al., 2007).

Energy balance, eating disorders, sports activity, body weight, and body mass index are basic factors associated with menstrual dysfunction in female athletes (FIMS Position Statement, 2000). According to Drinkwater (1984), the large variations in the prevalence of menstrual dysfunction in female athletes may be due not only to the factors mentioned above, but also to the studied population.

\section{Aim of the study:}

In Bulgaria, screening studies for eating disorders and menstrual dysfunctions in female athlete shave not been conducted. The aim of the present study was to determine the prevalence of menstrual dysfunction among female athletes and to examine the importance of disordered eating behaviors and other selected factors for its occurrence.

\section{Material and methods:}

The present study was approved by the Ethics Committee of the National Sports Academy. All respondents, after informed consent and detailed 
instructions, completed 2 paper-based questionnaires - 281 women aged 16-25 practicing different sports - aesthetic sports $(\mathrm{n}=70)$, sports games $(\mathrm{n}=$ $56)$, athletics $(n=35)$, water sports $(n=30)$, combat sports $(n=35)$, fitness $(n=19)$, short track $(n=19)$ and other sports $(\mathrm{n}=17)$ participated in the study. Menstrual status questionnaire was meant to identify the following menstruation dysfunctions: oligomenorrhea - menstrual bleeding at intervals longer than 36 days; primary amenorrhea - lack of menstruation cycle up to 16 years of age; secondary amenorrhea - the absence of menstruation cycle for 3 consecutive months after the onset of menarche. Also the questionnaire included questions about the age of menarche and the use of contraceptives.

The women athletes were divided into 2 groups according to their menstruation status - eumenorrheic (EM) and with menstrual dysfunction (MD) (amenorrhea/oligomenorrhea). Screening for eating disorders was conducted using the Eating Disorder Examination Questionnaire (EDE-Q 6.0) (Fairburn et al., 2014), which is composed of 4 subscales: $\mathrm{Di}$ etary Restraint (DR), Eating Concern (EC), Shape Concern (SC), Weight Concern (WC) as well as Global Score (GS). The GS was calculated as an arithmetic mean of the 4 subscale scores. In addition to subscales, the questionnaire provides assess the presence of some pathogenic behaviors related to nutrition and maintenance of low weight: binge eating, self-induced vomiting, use of laxatives, or intentional intensive physical exercise aimed to control the weight (Fairburn et al., 2014).

A mean cut-off of $\geq 4.0$ for the subscales WC, SC, DR or GS was used to classify the athletes as having clinical significant disordered eating (Nichols

Table 1. Percentage of athletes with disordered eating and/or menstrual dysfunction

\begin{tabular}{|c|c|c|}
\hline \multicolumn{2}{|c|}{ ( } & Whole sample $(n=281)$ \\
\hline Eumenorrhe & & $91.10 \%(n=256)$ \\
\hline $\begin{array}{r}\text { Menstrual d } \\
- \\
- \\
-\end{array}$ & $\begin{array}{l}\text { tion } \\
\text { Primary amenorrhea } \\
\text { Secondary amenorrhea } \\
\text { Oligomenorrhea }\end{array}$ & $\begin{array}{l}8.9 \%(\mathrm{n}=25) \\
3.20 \%(\mathrm{n}=9) \\
2.85 \%(\mathrm{n}=8) \\
2.85 \%(\mathrm{n}=8)\end{array}$ \\
\hline $\begin{array}{r}\text { EDE-Q Subs } \\
- \\
- \\
- \\
-\end{array}$ & $\begin{array}{l}\text { ore } \geq 4,0 \\
\text { Dietary restraint } \\
\text { Shape Concern } \\
\text { Weight Concern } \\
\text { Global Score }\end{array}$ & $\begin{array}{c}16.63 \%(\mathrm{n}=47) \\
6.05 \%(\mathrm{n}=17) \\
13.88 \%(\mathrm{n}=39) \\
8.90 \%(\mathrm{n}=25) \\
4.27 \%(\mathrm{n}=12)\end{array}$ \\
\hline $\begin{array}{r}\text { Pathogenic } \\
- \\
- \\
- \\
- \\
\end{array}$ & $\begin{array}{l}\text { or } \\
\text { Binge eating } \\
\text { Self-induced vomiting } \\
\text { Use of laxatives } \\
\text { Excessive exercise } \\
\end{array}$ & $\begin{array}{c}36.3 \%(\mathrm{n}=102) \\
34.88 \%(\mathrm{n}=98) \\
1.78 \%(\mathrm{n}=5) \\
7.47 \%(\mathrm{n}=21) \\
22.42 \%(\mathrm{n}=63) \\
\end{array}$ \\
\hline \multicolumn{2}{|c|}{ Both menstrual dysfunction and disordered eating } & $4.98 \%(\mathrm{n}=14)$ \\
\hline
\end{tabular}

et al., 2007). Pathogenic behavior was considered as of clinical severity if pathogenic eating behaviors was reported on $\geq 2$ days in the preceding 28 days (Nichols et al., 2007) or if excessive exercise for controlling the weight was practiced $\geq 5$ days in a week (Luce et al., 2008).

Statistical analyzes were performed using SPSS-23.0. Descriptive statistics was used to determine the mean and standard deviation (SD) for socio-demographic characteristics and EDE-Q subscales. An independent-samples t-test was conducted to compare all quantitative variables. The comparison of the mean values of EDC-Q subscales was performed by U-criterion of Man Whitney. The Pearson criterion $\chi^{2}$ was used to compare prevalence rates for menstruation and nutrition disorders.

\section{Results:}

The whole group of studied female athletes consisted of 281 female athletes from different sports. The results showed that the majority of them $-91.10 \%$ $(n=256)$ are eumenorrheic and 8.9\% $(n=25)$ had menstrual abnormalities (Table 1).

The cases of clinically significant eating disorders, determined on the basis of estimates of subscales SC, WC, DR, or GS $\geq 4.0$, were $16.63 \%$ of the whole group of athletes. The frequency of use of pathogenic weight control behaviors among sportswomen was $36.3 \%(n=102)$, with some of the female athletes having more than one pathogenic behavior. The higher was the incidents of binge eating $-34.8 \%$ and excessive exercise training in order of maintenance of low weight $-22.4 \%$. Both menstrual dysfunction and disordered eating were observed in $4.98 \%(n=14)$ of the studied women. 
We divided the subjects into two subgroups according to menstrual status (with normal menstrual cycle and with menstrual dysfunction) and compared their socio-demographic characteristics (Table 2).

The average age of the group of female athletes with normal menstrual cycle $(20.0 \pm 2.36 y)$ was higher $(\mathrm{p}<0.05)$ than that of the group with menstru- al dysfunction $(18.84 \pm 2.70 \mathrm{y})$. In terms of height, weight, BMI, sports experience and oral contraceptives intake there weren't statistically significant differences between both studied groups. More than one year, however, is the difference in the mean age at menarche between both groups and for female athletes with menstrual dysfunction menarche appears later.

Table 2. Socio-demographic characteristics of female athletes (mean \pm SD)

\begin{tabular}{|l|c|c|}
\hline Characteristics & $\begin{array}{c}\text { Eumenorrheic group } \\
(\mathbf{n = 2 5 6})\end{array}$ & Menstrual dysfunction group(n=25) \\
\hline Age $($ years $)$ & $20.00 \pm 2.36$ & $18.84 \pm 2.70^{*}$ \\
\hline Height $(\mathrm{cm})$ & $168.21 \pm 86.23$ & $166.76 \pm 8.77$ \\
\hline Weight $(\mathrm{kg})$ & $58.13 \pm 8.32$ & $56.96 \pm 8.47$ \\
\hline BMI $\left(\mathrm{kg} / \mathrm{m}^{2}\right)$ & $20.51 \pm 2.11$ & $20.53 \pm 3.06$ \\
\hline Age at menarche $(\mathrm{y})$ & $13.39 \pm 1.55$ & $14.50 \pm 1.51^{* *}$ \\
\hline Sports experience (y) & $8.42 \pm 4.42$ & $8.62 \pm 4.65$ \\
\hline Oral contraceptive use $(\%)$ & $11.3 \%(\mathrm{n}=29)$ & $24 \%(\mathrm{n}=6)$ \\
\hline
\end{tabular}

${ }^{*} \mathrm{p}<0.05,{ }^{* *} \mathrm{p}<0.01$

As can be seen from Table 3 there was not a significant difference between the mean values of the subscales of EDE-Q between tested groups.

Table 3. Results from EDE-Q for athletes (mean \pm SD)

\begin{tabular}{|l|c|c|c|}
\hline EDE-Q Subscale & $\begin{array}{c}\text { Whole sample of ath- } \\
\text { letes(n=281) }\end{array}$ & $\begin{array}{c}\text { Eumenorrheic group } \\
(\mathbf{n}=\mathbf{2 5 6})\end{array}$ & $\begin{array}{c}\text { Menstrual dysfunction } \\
\text { group }(\mathbf{n}=\mathbf{2 5})\end{array}$ \\
\hline Dietary restraint & $1.42 \pm 1.44$ & $1.42 \pm 1.46$ & $1.35 \pm 1.28$ \\
\hline Eating Concern & $0.79 \pm 0.94$ & $0.79 \pm 0.93$ & $0.75 \pm 1.04$ \\
\hline Shape Concern & $1.93 \pm 1.53$ & $1.91 \pm 1.51$ & $2.10 \pm 1.73$ \\
\hline Weight Concern & $1.67 \pm 1.47$ & $1.66 \pm 1.44$ & $1.76 \pm 1.76$ \\
\hline Global Score & $1.45 \pm 1.17$ & $1.45 \pm 1.17$ & $1.49 \pm 1.25$ \\
\hline
\end{tabular}

${ }^{*} \alpha<0.05,{ }^{* *} \alpha<0.01$

In order to determine whether the occurrence of menstruation disorders has been related to the nutritional pathology, we compared the prevalence of cases with a clinically significant eating disorder (score $\geq 4.0$ for the corresponding EDE-Q subscales) or of pathogenic behavior in both studied groups. (Table 4).

Table 4. Incidents of EDE-Q subscale score $\geq 4.0$ in both menstrual status groups

\begin{tabular}{|l|c|c|}
\hline EDE-Q Subscale score $\geq \mathbf{4 . 0}$ & Eumenorrheic group(n=256) & $\begin{array}{c}\text { Menstrual dysfunction } \\
\text { group(n=25) }\end{array}$ \\
\hline Dietary restraint & $6.25 \%(\mathrm{n}=16)$ & $4 \%(\mathrm{n}=1)$ \\
\hline Shape Concern & $13.28 \%(\mathrm{n}=34)$ & $20 \%(\mathrm{n}=5)$ \\
\hline Weight Concern & $7.81 \%(\mathrm{n}=20)$ & $20 \%(\mathrm{n}=5)^{*}$ \\
\hline Global Score & $4.30 \%(\mathrm{n}=11)$ & $4 \%(\mathrm{n}=1)$ \\
\hline Binge eating & $35.55 \%(\mathrm{n}=91)$ & $28 \%(\mathrm{n}=7)$ \\
\hline Self-induced vomiting & $1.95 \%(\mathrm{n}=5)$ & $16 \%(\mathrm{n}=0)$ \\
\hline Use of laxatives & $6.64 \%(\mathrm{n}=17)$ & $12 \%(\mathrm{n}=3)$ \\
\hline Excessive exercise & $23.44 \%(\mathrm{n}=60)$ & \\
\hline
\end{tabular}

${ }^{\star} a<0.05,{ }^{* \star} a<0.01$

The incidence of cases with clinically significant eating disorders in the group of female athletes with normal menstruation cycle did not differ significantly from the group of athletes with menstrual dysfunction for DR and SC subscales, as well as for
GS. Only the results of WC subscale of EDE-Q for the oligomenorrhea/amenorrhea group 20\% $(n=5)$ were significantly higher than that for eumenorrheic group $-7.81 \%(n=20)$. 
The results for use of pathological weight-making behaviors were similar. For female athletes with eumenorrhea they were as follows: binge eating $35.55 \%(\mathrm{n}=91)$; self-induced vomiting $1.95 \%(\mathrm{n}=$ 5); use of laxatives $6.64 \%(n=17)$; excessive exercise $23.44 \%(\mathrm{n}=60)$. The corresponding frequencies for the group of women athletes with menstruation disorders were: binge eating 28\% $(n=7)$; self-induced vomiting $0 \%(\mathrm{n}=0)$; use of laxatives $16 \%(n=4)$; excessive exercise $12 \%(n=3)$. The comparisons between both groups failed to detect any significant differences in the practice of pathological nutritional behaviors.

\section{Discussion:}

This study has shown relatively low rates (8.9\%) of menstruation dysfunction in female athlete. The later appearance of menarche in female athletes with menstruation dysfunction could not be explained by such factors as lower fat deposition due to the lack of differences in body weight and BMI in both groups. Similar results were obtained from Nichols et al (2006), who reported first menstruation 6 months later in female athletes with menstrual abnormalities as compared to eumenorrheic athletes. No differences were also observed with regard to sporting experience or the use of contraceptives. We found out a relatively high prevalence $(36.3 \%)$ of pathogenic behaviors (binge eating; self-induced vomiting; use of laxatives or excessive exercise) among the studied female athletes. Close proportions of pathogenic behaviors (32\%) were reported for African-American sportswomen (Rosen et al., 1986). However, studies in Norway have found lower frequencies of pathological weight loss methods - 25\% (Borgen, Larsen, 1993).

The prevalence of clinically significant eating disorders was $16.63 \%$ and was similar to data reported by Nichols et al. (2006) (18\%) and Beals \& Manore (2002) (15.2\%). Intergroup differences were found only in terms of WC subscale results, which was significant higher in female athletes with menstrual dysfunction (20\%), as compared to eumenorrheic athletes $(7.81 \%)(\alpha<0.05)$.

The cases of both menstrual dysfunction and disordered eating were relatively low $-4.98 \%$ of the tested female athletes.

\section{Conclusion:}

The results of our study showed that the prevalence of menstrual disturbances among Bulgarian female athletes is not high. However, the percentage of sportswomen with pathogenic eating behaviors is significant, which increases the risk to their long term health.

The results suggest that none of the factors studied weight, BMI, sports experience, age at menarche, the presence of eating disorders could explain the occurrence of menstrual dysfunction in female athletes.

\section{Reference:}

American Academy of Pediatrics: Committee on Sports Medicine: Amenorrhea in adolescent athletes. (1989) Pediatrics, 84(2):394-395.

Beals, KA., Manore, MM. (2002) Disorders of the female athlete triad among collegiate athletes. Int J Sport $\mathrm{Nu}$ trExercMetab.12(3): 281-293.

Borgen, JS., Larsen, S. (1993) Pathogenic weight-control methods and self-reported eating disorders in female elite athletes and controls. Scand J Med Sci Sports. 3(3): 150-155.

Fairburn, G., Cooper Z., O'Connor, M. (2014) Eating Disorder Examination (Edition 17.0D; April 2014) http://www.credo-oxford.com/pdfs/EDE 17.0D.pdf

FIMS Position Statement: June 2000. The Female Athlete Triad. A statement for health professionals from the Scientific Commission of the International Federation of Sports Medicine (FIMS): http://www.fims.org/ files/8214/2056/2594/PS14-The-Female-Athlete-Triad. pdf.

Forsberg, S. and Lock, J. (2006) The relationship between perfectionism, eating disorders and athletes: a review. Minerva Pediatr.58(6):525-536.

Loucks, AB. (2003) Energy availability, not body fatness, regulates reproductive function in women. Exerc Sport Sci Rev. 31(3):144-148.

Luce, KH., Crowther, JH., Pole, M. (2008) Eating disorder examination questionnaire (EDE-Q): Norms for undergraduate women. Int J Eat Disord. 41(3):273-276.

Nattiv, A., Loucks, AB., Manore, MM., Sanborn, CF., Sundgot-Borgen, J., Warren, MP. (2007) American College of Sports Medicineposition stand. The Female Athlete Triad. Med Sci Sports Exerc.39(10): 1867-1882.

Nichols, JF., Rauh, MJ., Barrack, MT., Barkai, HS., Pernick, Y. (2007) Disordered eating and menstrual irregularity in high school athletes in lean-build and nonlean-build sports. Int J Sport NutrExercMetabol. 17(4), 364-377.

Nichols, JF., Rauh, MJ., Lawson, M., Ji, M., Barkai, HS. (2006) Prevalence of the Female Athlete Triad syndrome among high school athletes. Arch Pediatr Adolesc Med.160(2):137-142.

Raymond-Barker, P., Petroczi, A., Quested, E. (2007) Assessment of nutritional knowledge in female athletes susceptible to the female athlete triad syndrome. J Occup Med Toxicol. 2:10.

Rosen, LW., McKeaG, DB., Hough, DO., Curley, V. 
(1986) Pathogenic weight-control behaviors in female athletes. Phys Sports med. 14(1): 79-86.

Roupas, ND. and Georgopoulos, NA. (2011) Menstrual function in sports. Hormones 10(2): 104-116.

\section{Acknowledgments:}

This research was supported from National Sports Academy by grant No83/2015. The funding organization did not participate in the design or conduct of the study; in the collection, analysis, or interpretation of the data; or in the preparation of the manuscript.

Authors greatly appreciate all athletes and students at National Sports Academy "V. Levski" who participated in this study.

\section{Address for corresponds:}

Galina Vanlyan, MD

National Sports Academy, Department of Sports Medicine

Phone/ Fax: (+359) 899846949

1700 Sofia, Bulgaria

E-mail: galina vanlyan@abv.bg

Prof. Diana Dimitrova, MD, PhD

National Sports Academy, Department of Sports Medicine

Phone/ Fax: (+359) 898776281

1700 Sofia, Bulgaria

E-mail: dianansa@yahoo.com 